\title{
Study on Cost Economics of both Polymer and Metal Centrifugal Pumps
}

\author{
A. Rama Rao ${ }^{1 *}$, G. Ravi Babu², D. Bhaskara $\operatorname{Rao}^{3}$ and V. Srinivasa $\operatorname{Rao}^{4}$ \\ ${ }^{1}$ Krishi Vigyan Kendra, Kondempudi, Visakhapatnam, India \\ ${ }^{2}$ Department of Irrigation and Drainage Engineering, College of Agricultural Engineering, \\ Bapatla, India \\ ${ }^{3}$ Acharya N.G. Ranga Agricultural University, Guntur, India \\ ${ }^{4}$ Department of Statistics and Mathematics, Agricultural College, Bapatla, India \\ *Corresponding author
}

\begin{tabular}{|c|}
\hline Keywords \\
\hline $\begin{array}{l}\text { Centrifugal pumps, } \\
\text { cost, Polymers, } \\
\text { Advantages and } \\
\text { components }\end{array}$ \\
\hline Article Info \\
\hline $\begin{array}{l}\text { Accepted: } \\
18 \text { September } 2018 \\
\text { Available Online: } \\
10 \text { October } 2018\end{array}$ \\
\hline
\end{tabular}

\section{Introduction}

Pumps transform mechanical energy into hydraulic energy, usually to increase the pressure in the liquid either to compress it or to move it from one place to another. There are many technical disadvantages in the present existing metallic centrifugal pumps namely (i) weight of the pump (ii) considerable wear and tear (iii) high frictional resistance (iv) high power consumption (v) low pump efficiency (vi) corrosion (vii) poor ergonomics (noise and electrical shocks) (viii) cost of the pump and (ix) pump life. To 
overcome these technical disadvantages of existing metal centrifugal pump, alternative materials are required to replace the metals. Seven polymeric materials (engineering plastics) of thermostat category like Nylon, Poly Phenolic Oxide (PPO) also called Noryl, Modified nylon named as Delrin, Vespel, Zytel, Ultra High Molecular Weight Poly Ethelin (UHMWPE) and Poly Ethyl Ether Keeton (PEEK) are commercially available in the market. It is found that polymeric materials have several better mechanical, chemical, thermal and electrical properties over metals like i) excellent load bearing capacity strength) ii) corrosion resistance iii) light weight $\left(1 / 8^{\text {th }}\right.$ weight of steel) iv) low coefficient of friction $v$ ) chemical resistance vi) excellent wear resistance vii) reduced wear on matching parts viii) cost - able in large profile xi) near net shape capacity $\mathrm{x}$ ) good insulator xi) easy to maintain and xii) excellent dimensional stability.

Bolade and Madki (2014) worked on design of centrifugal pump for high temperature fluid. During the design of pump at high temperature, the requirements of longer life and reliability have to be balanced by the constraint of high initial cost and efficiency. The materials for construction of pump above the $350^{\circ} \mathrm{C}$ were cast steel American Society for Testing Materials (ASTM) A 216/ 216M (casing and impeller), cast steel (wear ring), ASTM A 343-4140 CL BB annealed (shaft and shaft sleeve), cast iron-210 FG-260.

Das and Nizam (2014) studied the application of Fiber Reinforced Polymer (FRP) composites in civil engineering. It reveals that FRPs were non-corrosive, high strength and modulus value compared to their density; light weight, acceptable deformability, tailored design and excellent formability enable the fabrication of new element and the structural rehabilitation of the existing parts made of traditional material. Furthermore, the resistance of FRP materials to corrosion means that they could be used to replace steel and reinforced concrete in situation when they would be exposed to corrosion. It was suggested that many polymer like glass fibers, carbon fibers, aramid fibres, basalt fibres, thermoplastic, thermosetting, polyester resin, epoxy resign and vinyl ester resign.

Langhals et al., (2014) identified technical polymers by means of their remarkably strong auto fluorescence. The time constants of this fluorescence proved to be characteristic for the individual polymers and could be economically determined by integrating procedures. The obtained unequivocal identification was presented for their sorting for recycling.

Vohra and Vyas (2014) reported that gears were generally made from metallic materials but recently advanced polymers materials were developed with sufficient strength and properties similar to the metallic materials. Nylon, polycarbonate, acetals and Delrin were the structure polymers materials were used for gears in printing and robotics mechanism with good functionality but polymers gears were not used in heavy loading type application. Specially polymers gives extra benefits compared to metallic gears like less noisevibration, low requirement of maintenancelubrication, low cost and easy manufacturing. Static finite element analysis requires performing the design optimization process on both materials.

Kesbe et al., (2013) studied the phenomenon of cavitation of centrifugal pumps remains of a great importance in the field of construction as well as in the field of installation of pumps in pumping stations. In fact, with the consequences it engenders noise, vibration, erosion and loss of efficiency, it provokes on hand, a progressive degradation of the performance of the machine and on the other 
hand and increase in the costs of the maintenance of installation in addition to the loss of efficiency of pumps and the resistance of different materials to the effects of the phenomenon of cavitation. Among the techniques and methods of protecting the parts of pumps was the cladding of the parts with composite plastic materials for the purpose of increasing the resistibility and protecting the parts from the effects of cavitation.

Reddy and Reddy (2013) presented that manufacturing of dies require presenting greater requirements of geometrical accuracy, dimensional precision and surface quality as well as decrease in costs and manufacturing times. In milling process; cutting speed, step over and feed were the main cutting parameters and these parameters affect geometrical accuracy and surface quality of the casting die cavities. Effects of the cutting parameters on geometrical error have been examined on a representative die cavity profile. To remove undesired volume in the die cavities, available cutting strategies were investigated. Finish option for roughing and finish option for finishing were optimized to reduce the machining time of the cutting process thereby decreasing the cost of cutting process.

Gururaja and Rao (2012) studied the recent applications and future prospectus of hybrid composites. Hybrid composite materials have extensive engineering application where strength to weight ratio, low cost and ease of fabrication were required. Hybrid composites provide combination of properties such as tensile modulus, compressive strength and impact strength which cannot be realized in composite materials. It was presented a review of the current status of hybrid composite materials technology, in terms of materials available and properties and an outline of some of the trends, obvious and speculative, with emphasis on various applications including some details of smart hybrid composites.

\section{Materials and Methods}

The pumps used in agriculture, domestic, industrial and power generation needs optimum conditions to withstand active and dead loads, pressures and environmental conditions. The present study was carried out at Central Institute of Plastics Engineering and Technology (CIPET), Hyderabad, Central Institute of Tool Design (CITD), Hyderabad and College of Agricultural Engineering, Bapatla. The local made cast iron pulley operated centrifugal pump was selected for study of the present study. As an alternative to dimensional analysis of the polymer pump design Coordinates Measuring Machine (CMM) was chosen and Computational Fluid Dynamics (CFD) was chosen for simulation and to test the metal pump dimensions suitability in order to withstand all the properties accordingly explore the possibilities for testing and developing the dimensions at CIPET and CITD performance were done after many technical interactions. The components of selected centrifugal pump for research work are casing, impeller, shaft, pulley, baring stand, baring cover, bottom flange, top flange, gland, counter weight and base which are made up with cast iron (Plate 1 and 2) and the polymer pump and its all components are shown in (Plate 3 and 4).

\section{Comparison of metal and polymer pump components weight}

After completion of machining both metal and polymer pump components individual weight was measured with electronic weighing machine. It was noticed that the total weight of the metal pump was $5.7 \mathrm{~kg}$ and polymer pump was $1.7 \mathrm{~kg}$ shown in the (Plate 5 and 6) and the difference of weight between two pumps was identified as more than $4 \mathrm{~kg}$. It 
means the weight of the metal pump by use of polymers could reduce drastically. The individual weights of both pump components were differentiated and presented in Table 1. By replacing the metal pump with the polymer pump components the weight of the pump was reduced by 70 per cent and could be made very light in weight.

\section{Results and Discussion}

Both the polymer pump and metal pumps were connected by a 35 inch $\mathrm{B}$ groove $\mathrm{V}$ - belt and operated for trails of discharge measurement with $0.25 \mathrm{hp}$ and $0.5 \mathrm{hp}$ single phase induction motor. The pump was run successfully for a period of $10 \mathrm{~h}$ in 5 intervals (Plate 7) and the polymer pump went on several trails up to 10 pumping hours and great heat was developed due to continuous rotation of shaft with the speed of $2700 \mathrm{rpm}$. It produced Heat due to this the packing rope placed in between casing and shaft, started melting and the liquid entered into the gland finally made the shaft stuck-up. For avoiding the problem of shaft struck in the gland the packing rope was replaced by a rubber oil seal. The polymer pump performance was tested in working condition in field irrigation laboratory at College of Agricultural Engineering, Bapatla (Plate 8). The stream flow distance of both metal and polymer pump was measured as $1.5 \mathrm{~m}$ minimum and maximum $1.8 \mathrm{~m}$ (Plate 9 and 10). The rotation of both polymer pump and metal pump at pulley and motor were recorded with a digital tachometer.

\section{Cost economics of polymer pump and metal pump}

The CIPET(Central Institute of Plastics Engineering and Technology), Hyderabad, a central government institution, a unit of Department of Chemicals and Petro
Chemicals, Ministry of Chemicals and Fertilizers, Govt. of India has given production cost estimation of all the polymer pump components individually.

The casing of the polymer pump was highest cost of Rs.8 lakh and its counter weight was the lowest cost of Rs.1 lakh and the total polymer pump mold cost was Rs. 24.5 lakh. A mold is useful for mass production of the jobs. The components used for 1 lakh pieces minimum and 5 lakh pieces maximum. The payback period of mold cost would be very short. The individual polymer pump components and their mold cost were shown in Table 2.

The CIPET, Hyderabad, a unit of Department of Chemicals and Petro Chemicals, Ministry of Chemicals and Fertilizers, Govt. of India has given cost estimation for molding of all the polymer pump components individually. The base of the pump was highest in cost of Rs. 200 followed by casing cost of Rs.150 and their counter weight was the lowest in cost of Rs.12 and the total polymer pump production cost was Rs.485. The individual production cost of polymer pump and their components were shown in Table 3. The market price of metal pump used for present study was Rs.1200 which was more than double the cost of polymer pump.

Based on CIPET estimation, the production cost of one lakh polymer pumps were projected as Rs. 48500000 (Rs.4.85cr.) and metal pumps was Rs.120000000 (Rs.12 cr.) the differences was calculated as Rs. 71500000 (Rs.7.15cr.). The mold cost of polymer pump (Rs.24.5 lakh) was very little and negligible in foreseeing into the huge difference of $7.15 \mathrm{cr}$. The projected cost of one lakh polymer pumps and their cost are presented in Table 4. 
Table.1 Comparison of weight of metal and polymer pump components

\begin{tabular}{|c|l|c|c|c|}
\hline S. No. & \multicolumn{1}{|c|}{ Component } & Metal $(\mathbf{g})$ & Polymer $(\mathrm{g})$ & Difference $(\mathrm{g})$ \\
\hline $\mathbf{1}$ & Shaft & 200 & 200 & 000 \\
\hline $\mathbf{2}$ & Counter weight & 350 & 80 & 270 \\
\hline $\mathbf{3}$ & Pulley & 400 & 100 & 300 \\
\hline $\mathbf{4}$ & Bush/Gland & 110 & 25 & 85 \\
\hline $\mathbf{5}$ & Impeller & 315 & 60 & 255 \\
\hline $\mathbf{6}$ & Top flange & 230 & 30 & 200 \\
\hline $\mathbf{7}$ & Bottom flange & 2095 & 90 & 390 \\
\hline $\mathbf{7}$ & Casing & 970 & 470 & 1695 \\
\hline $\mathbf{9}$ & Pump base/Flat form & 520 & 190 & 500 \\
\hline $\mathbf{1 0}$ & Bearing stand & 30 & 30 & 330 \\
\hline $\mathbf{1 1}$ & Bearing cover & 5700 & 1675 & 00 \\
\hline & Total weight & & & 4025 \\
\hline
\end{tabular}

Table.2 Mold cost of polymer centrifugal pump and their components

\begin{tabular}{|c|l|c|c|}
\hline S. No. & \multicolumn{1}{|c|}{ Component } & Type of molding & Mold cost (Lakhs) \\
\hline 1. & Shaft & Injection molding & 2.0 \\
\hline 2. & Bearing stand (Including cover) & Injection molding & 3.0 \\
\hline 3. & Counter weight & Injection molding & 1.0 \\
\hline 4. & Pulley & Injection molding & 2.0 \\
\hline 5. & Bush or gland & Injection molding & 1.0 \\
\hline 6. & Impeller & Injection molding & 1.5 \\
\hline 7. & Top flange & Injection molding & 1.5 \\
\hline 8. & Bottom flange & Injection molding & 1.5 \\
\hline 9. & Casing & Injection molding & 8.0 \\
\hline 10. & Pump base & Injection molding & 3.0 \\
\hline & & & \\
\hline
\end{tabular}

Table.3 Production cost of polymer centrifugal pump and their components

\begin{tabular}{|c|l|l|c|}
\hline S. No. & \multicolumn{1}{|c|}{ Component } & Type of molding & Component cost (Rs.) \\
\hline 1. & Shaft & Injection molding & 15 \\
\hline 2. & Bearing stand (Including cover) & Injection molding & 35 \\
\hline 3. & Counter weight & Injection molding & 12 \\
\hline 4. & Pulley & Injection molding & 15 \\
\hline 5. & Bush or gland & Injection molding & 10 \\
\hline 6. & Impeller & Injection molding & 15 \\
\hline 7. & Top flange & Injection molding & 15 \\
\hline $\mathbf{8 .}$ & Bottom flange & Injection molding & 18 \\
\hline 9. & Casing & Injection molding & 150 \\
\hline $\mathbf{1 0 .}$ & Pump base & Injection molding & 200 \\
\hline & Total cost & & 485 \\
\hline
\end{tabular}


Table.4 Projection of production cost of 1 lakh polymer pumps

\begin{tabular}{|c|l|c|c|}
\hline S. No. Component & \multicolumn{1}{|c|}{$\begin{array}{c}\text { One component cost } \\
(\text { Rs.) }\end{array}$} & $\begin{array}{c}\text { One lakh components } \\
\text { cost (Rs.) }\end{array}$ \\
\hline 1. & Shaft & 15 & 1500000 \\
\hline 2. & Bearing stand including & 35 & 3500000 \\
\hline 3. & Counter weight & 12 & 120000 \\
\hline 4. & Pulley & 15 & 1500000 \\
\hline 5. & Bush or gland & 10 & 1000000 \\
\hline 6. & Impeller & 15 & 1500000 \\
\hline 7. & Top flange & 15 & 1500000 \\
\hline 8. & Bottom flange & 18 & 1800000 \\
\hline 9. & Casing & 150 & 15000000 \\
\hline 10. & Pump base & 200 & 20000000 \\
\hline & Total cost & 485 & 48500000 \\
\hline
\end{tabular}

Plate.1 Metal (Cast Iron) centrifugal pump selected for study

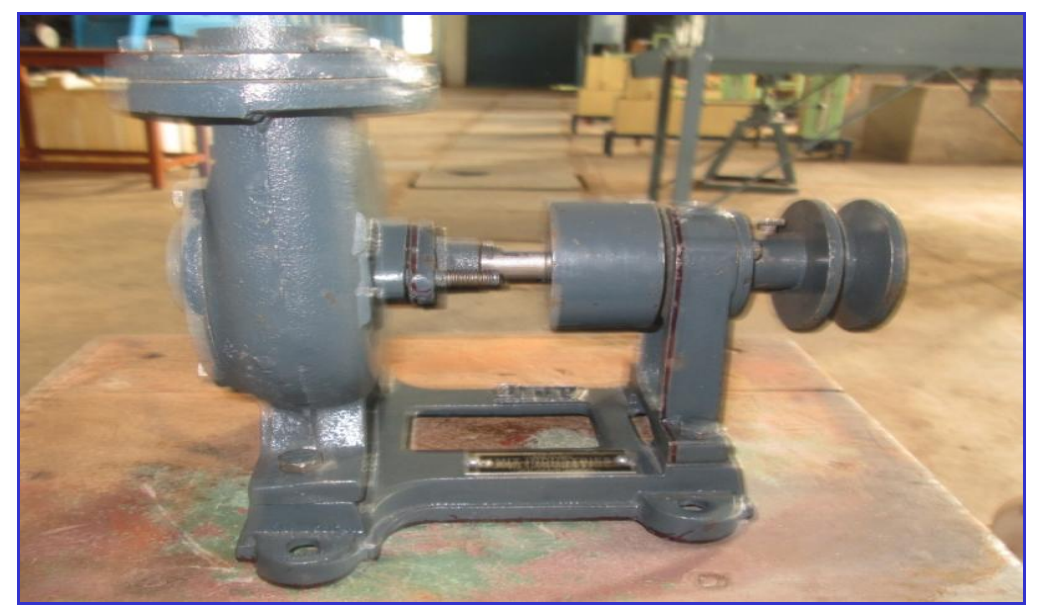

Plate.2 Components of the selected metal centrifugal pump

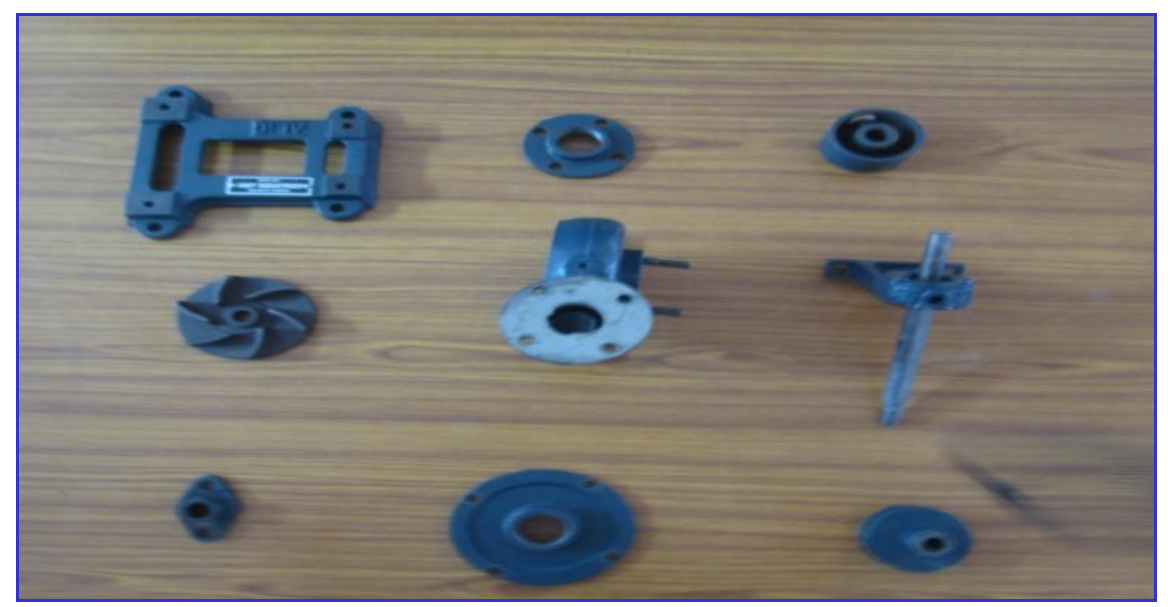


Plate.3 Assemble of polymer casted centrifugal pump

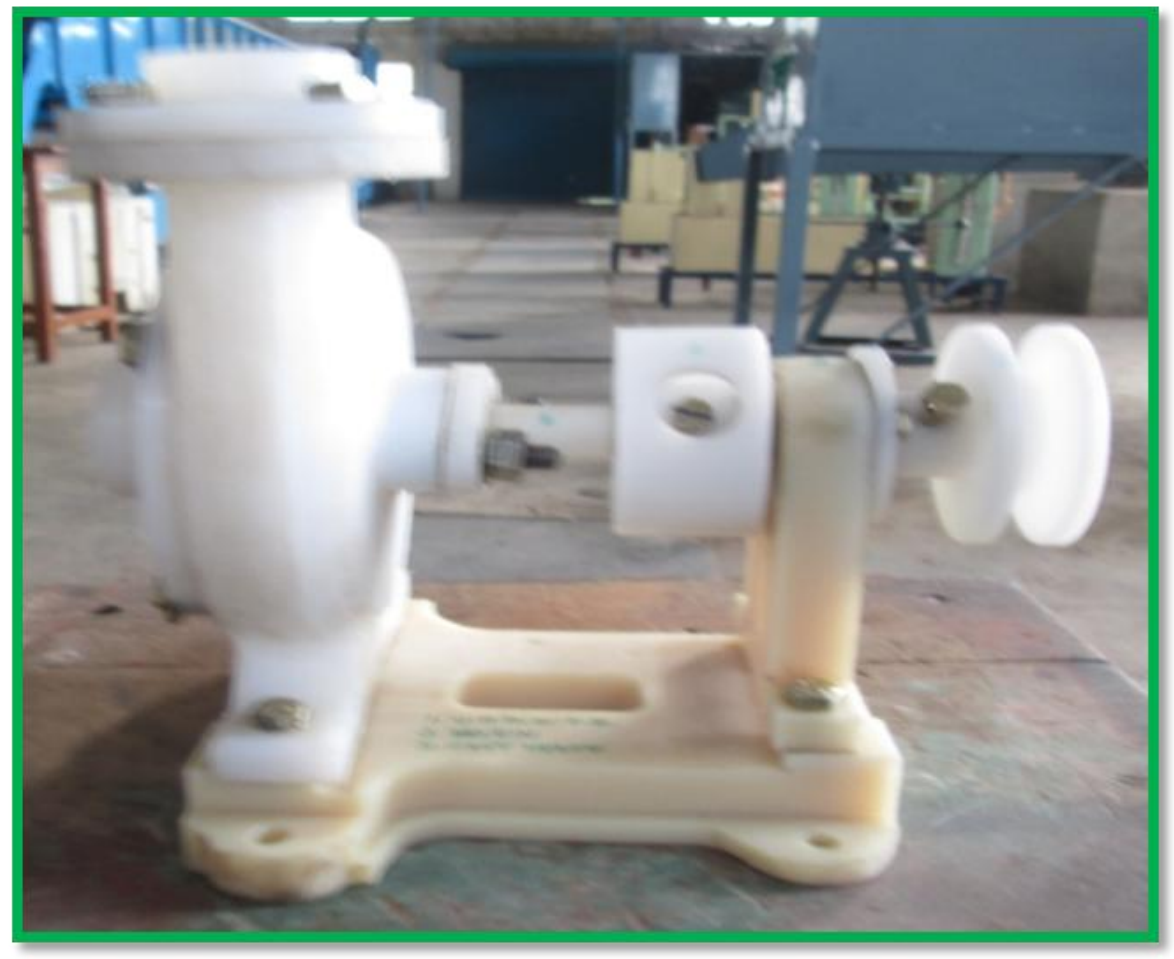

Plate.4 Components of polymer casted centrifugal pump

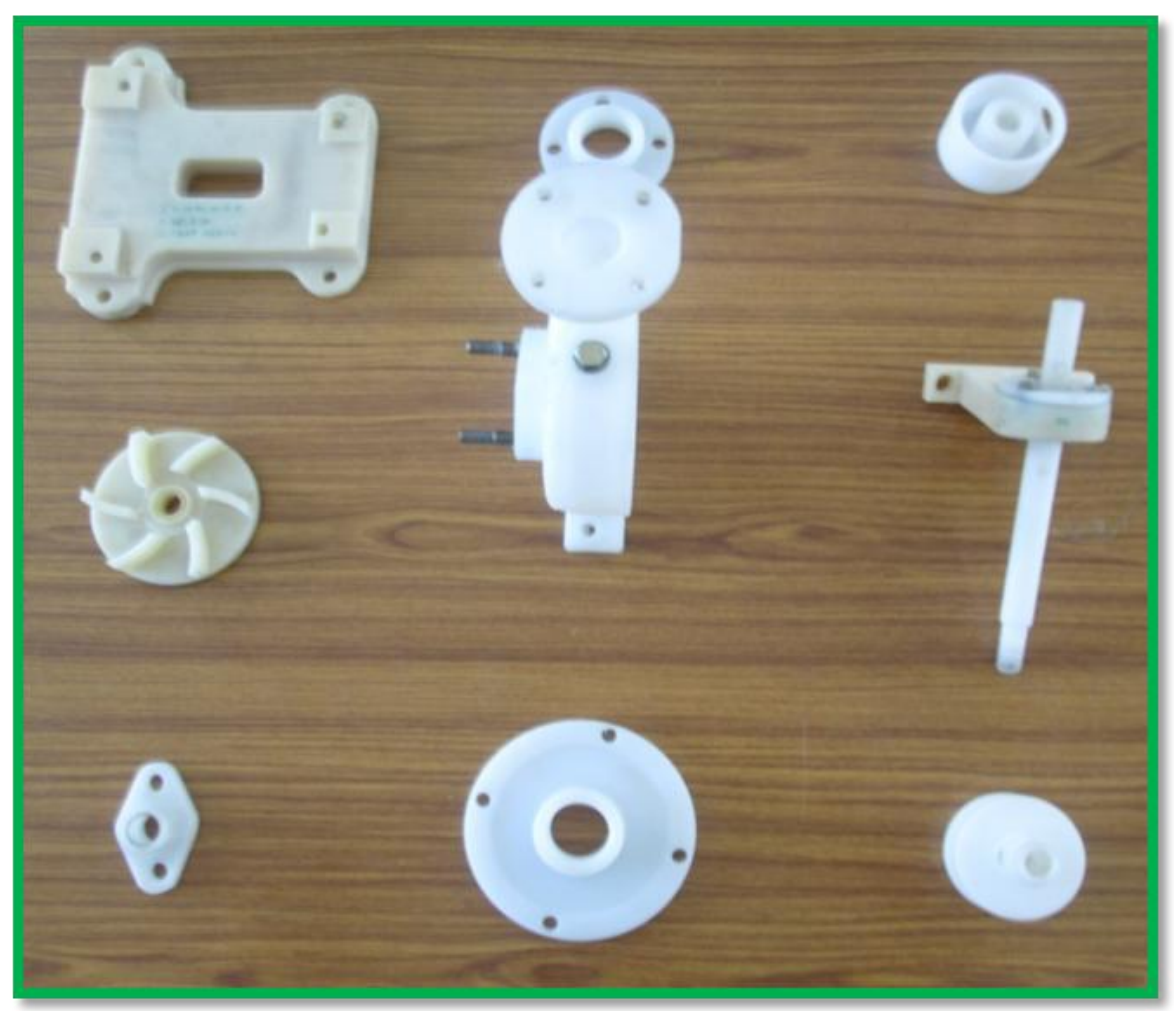


Plate.5 Weighing of polymer pump components on electronic weighing machine

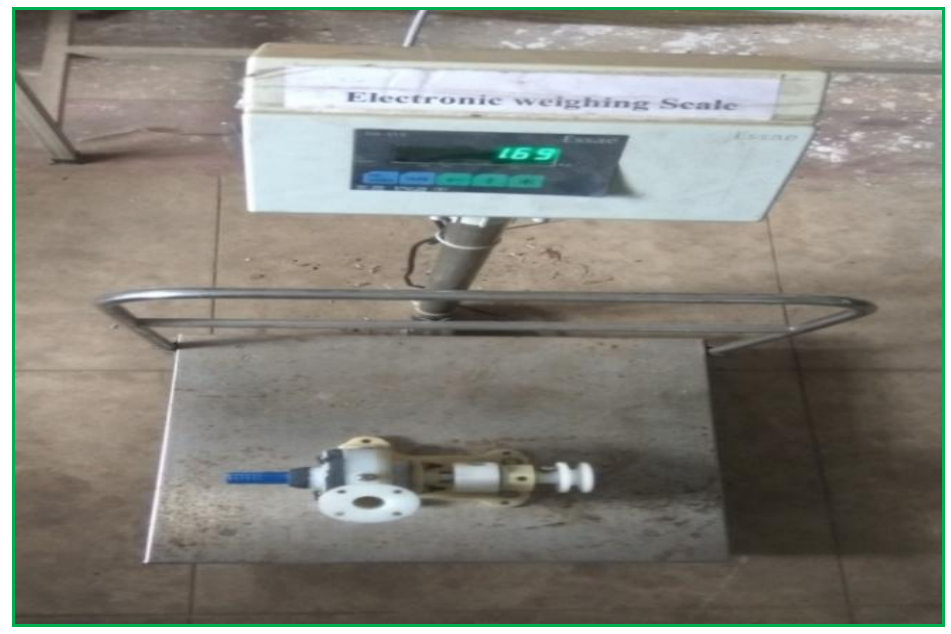

Plate.6 Weighing polymer pump on electronic weighing machine

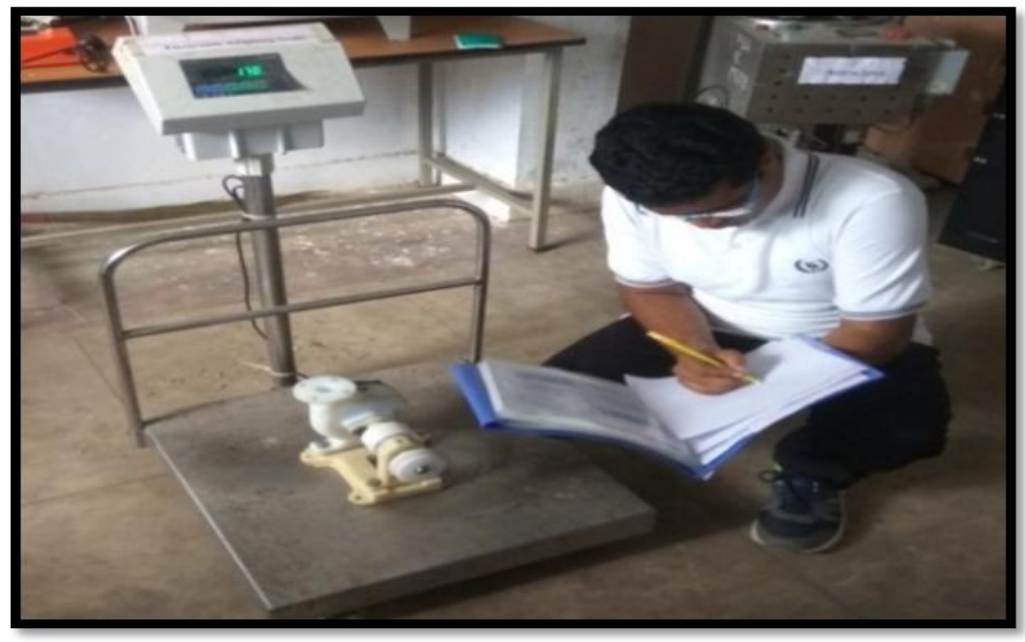

Plate.7 Polymer pump in operation in laboratory

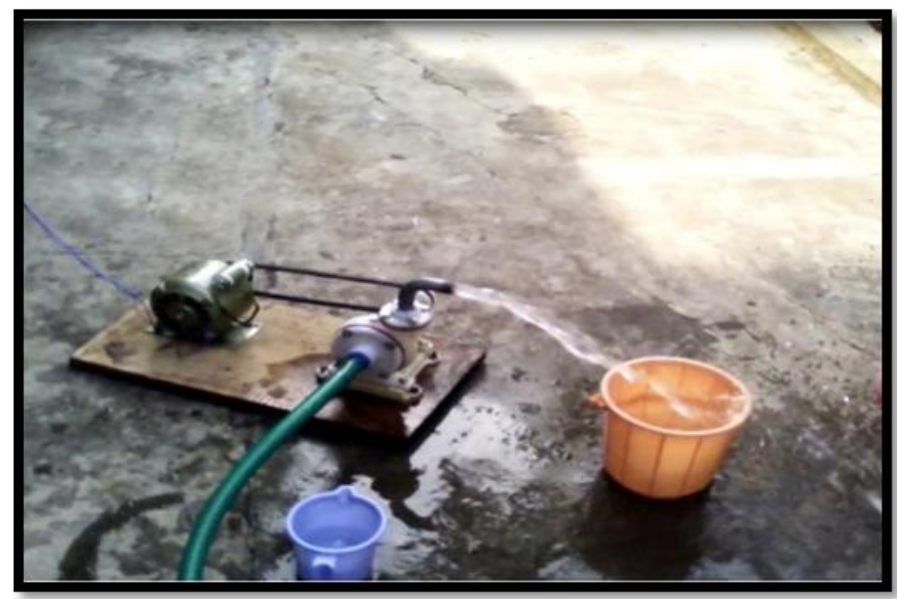


Plate.8 Working condition of polymer centrifugal pump

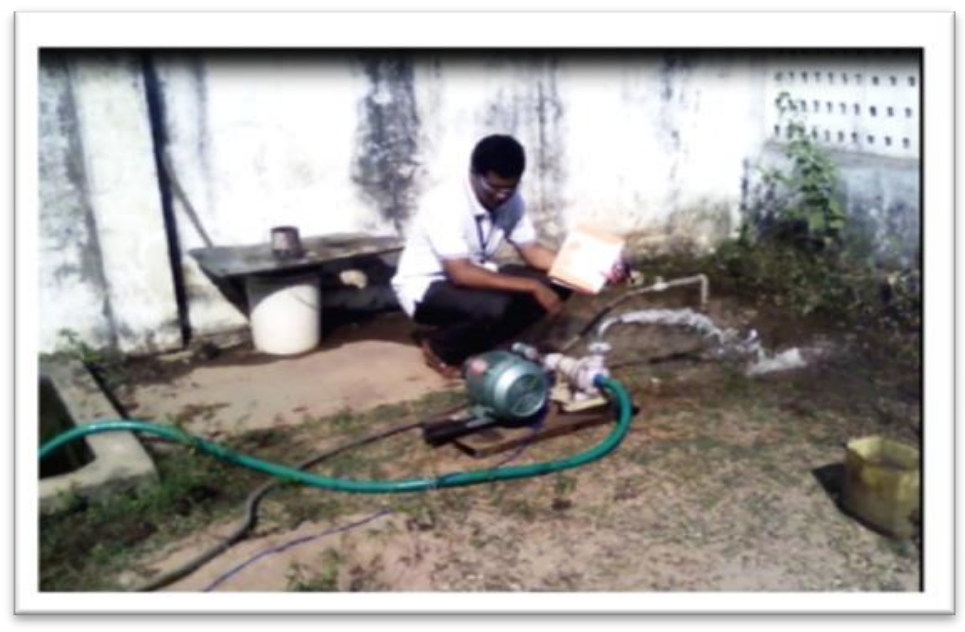

Plate.9 Measuring the distance of stream flow of polymer centrifugal pump

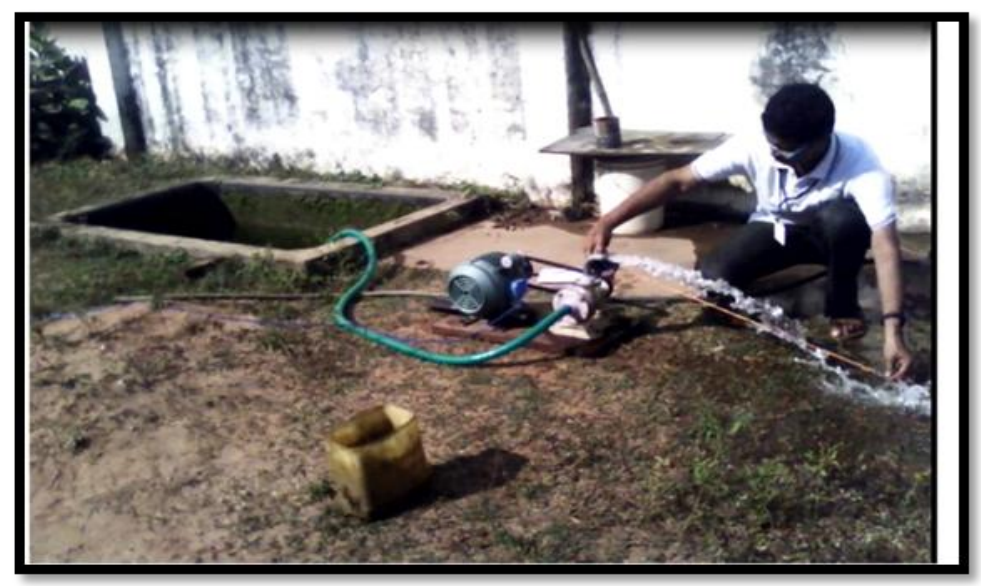

Plate.10 Metal centrifugal pump setup for experiment at an open well

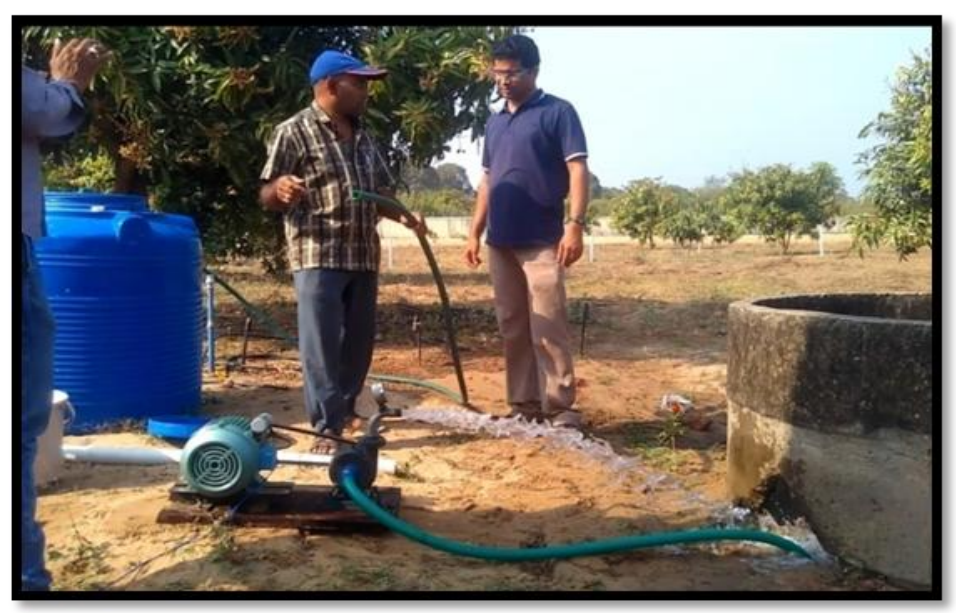


As per the capacity of mold, 5 lakh polymer pumps made a total production cost of Rs. $24.25 \mathrm{cr}$. and the metal pump market cost of 5 lakh pump sets are around Rs.60 cr. The Rs. $35.75 \mathrm{cr}$. is the difference of costs of both polymer and metal pumps. This huge amount can be given as subsidy to the farming community and as well as pump users. By replacing the present metal pump with the polymers 59.6 per cent cost could be reduced and made very cheap.

The mold cost of one polymer pump was Rs.24.5 lakh and production cost for one polymer pump was Rs.485 and at the same time the metal pump the market price was Rs. 1200.

The projected cost of 1 lakh polymer pumps was Rs. 4.85 cr. and 1 lakh metal pumps market price was Rs. 12 cr. and the difference of cost was Rs. $7.15 \mathrm{cr}$.

The projected cost of 5 lakh polymer pumps was Rs. 24.25 cr. and 5 lakh metal pumps market price was Rs. $60 \mathrm{cr}$. and the difference of cost was Rs. $35.75 \mathrm{cr}$.

By replacing the metal pump with the polymer pump the cost of the pump was reduced by 59.6 per cent and made very cheap.

\section{References}

Bolade, P.S. and Madki, S. J. 2014. Design of centrifugal pump for high temperature fluid. International Journal of Engineering and Technical Research. 2(9):244-246.

Das, S.C. and Nizam, E. H. 2014. Applications of fibber reinforced polymer composites (FRP) in Civil Engineering. International Journal of Advanced Structures and Geotechnical Engineering. 3(3):299-309.

Gururaja, M. N. and Rao, A. N. H. 2012. Review on recent applications and future prospectus of hybrid composites. International Journal of Soft Computing and Engineering. 1(6): 352-355.

Kesbe, O. K., Mitoubi, M. K. and Bourika, M. 2013. Study of the effect cavitation up on the wheels of different types of materials for pump. International Journal of Scientific and Technology Research. 14:299-304.

Langhals, H., Zgela, D. and Thorben, S. 2014. High performance recycling of polymers by means of their fluorescence lifetimes. Journal of Green and Sustainable Chemistry. 4(1):144150.

Reddy, R.S. and Reddy, R. K. 2013. Cutting strategies for casting die manufacturing on CNC milling machine. Journal of Mechanical and Civil Engineering. 7(4): 15-23.

Vohra, M. and Vyas, K. 2014. Design stress analysis of metallic and non-metallic spur gear - A Review. International Journal for Scientific Research and Development. 2(4): 125-128.

\section{How to cite this article:}

Rama Rao, A., G. Ravi Babu, D. Bhaskara Rao and Srinivasa Rao, V. 2018. Study on Cost Economics of both Polymer and Metal Centrifugal Pumps. Int.J.Curr.Microbiol.App.Sci. 7(10): 2277-2286. doi: https://doi.org/10.20546/ijcmas.2018.710.263 